\title{
PERFORMANCE OF SIX SIGMA REBALANCING FOR PORTFOLIOS MIXING POLAR INVESTMENT STYLES
}

\author{
Martin Bod'a1,2, Mária Kanderová ${ }^{1}$ \\ ${ }^{1}$ Quantitative Methods and Information Systems Department, Faculty of Economics, Matej Bel University \\ in Banská Bystrica, Národná 1, 97401 Banská Bystrica, Slovak Republic \\ 2 Department of Mathematics, Faculty of Natural Sciences, Ján Evangelista Purkyně University in Ústí nad Labem, \\ Pasteurova 1, 40096 Ústí nad Labem, Czech Republic
}

Link to this article: https://doi.org/10.11118/actaun202068010139

Received: 3. 6. 2019, Accepted: 2. 12. 2019

To cite this article: BOĎA MARTIN, KANDEROVÁ MÁRIA. 2020. Performance of Six Sigma Rebalancing for Portfolios Mixing Polar Investment Styles. Acta Universitatis Agriculturae et Silviculturae Mendelianae Brunensis, 68(1): 139155.

\begin{abstract}
The paper investigates usefulness of a rebalancing strategy that was proposed in 2014 by Bod'a and Roháčová and is based on ideas borrowed from the managerial concept Six Sigma. Centring upon a small investor who is willing to invest into S\&P 500 Index components in an attempt to track the S\&P 500 Index, the paper compares the performance of different rebalancing strategies for four different sets of monthly data ranging from 2011 to 2017. Rebalancing is undertaken on a monthly basis and tracking portfolios are diversified by investing in proportions into stocks belonging to investment styles defined by size (big/small caps) and market-to-book ratio (growth/value stocks). The results show that the Six Sigma rebalancing strategy is superior in a transaction-cost-free environment, but when transaction costs are accounted for, it is dominated by the buy-and hold strategy and a liberal threshold rebalancing strategy. Overall, periodic rebalancing fares unsatisfactorily with respect to criteria adopted for performance assessment.
\end{abstract}

Keywords: rebalancing, Six Sigma, big and small caps, growth and value stocks, quadratic tracking, performance

\section{INTRODUCTION}

In maintaining the return-risk profile of a portfolio throughout the investment horizon, periodic and threshold rebalancing are options that are viable to a small investor provided that they are undertaken in a somewhat mechanistic way. The obvious reason being, periodic and threshold rebalancing do not require a special software support. In the former approach portfolio revisions are implemented regularly without a particular assessment whether they are needed at the time or not. On the contrary, the latter approach requires additionally that the current portfolio composition (resulting from combining fixed asset holdings and current asset prices) is regularly checked whether there are deviations from the indented portfolio composition (optimized at the making of the investment) upon which portfolio revisions are introduced only when these deviations are significant. Admittedly, periodic rebalancing, as it is based merely on time, is the most popular portfolio rebalancing approach. Nonetheless, it goes without saying that other rebalancing strategies can provide better results. On and off, there emerge studies that compare rebalancing strategies with a conclusion that no universally applicable rebalancing strategy exists (e.g. Dichtl et al., 2014; Lam, 2014; Bod'a and Kanderová, 2018). Some enhancements of threshold rebalancing strategies go beyond simple comparisons of weights and include optimizations algorithm that also account for transaction costs and make updates 
of portfolio composition more sophisticated, posing thus more demands on investing (e.g. Mansini et al., 2015, pp. 75-78; Guastaroba et al., 2009; Glen, 2011). Although appealing from a technicist's point of view and indisputable veracity in capturing tiny nuisances of the investment process (such as trading limits or non-linearity in transaction costs), the implementability of these models for a small investor is questionable.

It is understandable that small individual investors have a tendency to rebalance periodically on an annual basis to simplify their investment process to the greatest degree possible, but it is the belief of the authors that more effort should be spent, and perhaps they should outstep traditional rebalancing approaches in order to make their portfolios continuously consistent with the adopted return-risk trade-off. Of course, useful are only rebalancing strategies that are implementable in a spreadsheet and easy to understand. One such strategy was put forward by Bod'a and Roháčová (2014) and is based on the Six Sigma methodology. This rebalancing approach may be somewhat onerous to a small investor since it requires updates of the data sets of historical returns in the frequency chosen for rebalancing, but calculations are not extra demanding in comparison to those in a threshold rebalancing strategy when an intervention is put to practice and can be managed easily in a spreadsheet. The Six Sigma approach to rebalancing applies ideas that are used in the manufacturing and service industries to improve operational performance by identifying and dealing with its deficiencies. A financial investment in a portfolio of assets over the investment horizon may be construed as a process whose goal is to retain the pre-set return-risk profile. Such a process is troubled by a deficiency whenever there is a discrepancy from the return-risk profile owing to market trends and developments, either in the form of a decreased mean return or increased volatility. One approach in Six Sigma to measure frequency of deficiencies is through the so-called sigma level, which is a general (yet perhaps no flawless) measure of portfolio quality. If the described deficiencies are too frequent, the sigma level of the portfolio worsens, which should be interpreted as an impetus for portfolio revision.

To the best knowledge of the authors, there is no proposal of a rebalancing strategy that would be grounded in Six Sigma ideas other than that of Bod'a and Roháčová (2014). Despite the authors demonstrating originally its merits, their case study can barely be depicted as exhaustive and properties of the method remain unknown. In recognition of suitability of the Six Sigma rebalancing strategy to a small (though not necessarily small) investor, the goal of the paper is to compare the performance and reliability of this rebalancing strategy with traditional rebalancing strategies based on time (periodic rebalancing) and on a tolerance level for intervention (threshold rebalancing). It is further operated on the suppositions that (1) a small investor would prefer investing into U.S. stocks for which real-time data are readily available and which is a popular investing choice; that (2) he would attempt at diversification by investing into stocks associated with different investment styles; and that (3) he would opt for a passive approach to portfolio selection. Toward this end, the comparison is handled as a case study of investing into S\&P 500 Index constituents in an effort to mimic the performance of the S\&P 500 Index fulfilling the role of a benchmark accordant to the returnrisk attitudes of a small investor. The investor is prepared to invest a modest sum of US $\$ 10,000$ into 40 S\&P 500 stocks at most under transaction costs. The invested sum is allocated into two polar classes of assets: big/small caps (the investment styles based on size by accepting market capitalization as the classification criterion) and value/growth stocks (the investment styles based on pricing by accepting the $\mathrm{P} / \mathrm{B}$ ratio for classification). These two categories of assets are mixed in various proportions including also a possibility that all is invested into a single category, which produces general "BG", "BV", "SG" and "SV" mixing portfolios. Using four different four-year data sets on a monthly frequency over the period from 2011 to 2017, the case study considers various choices that result in as many as 720 portfolios tracking the S\&P 500 that are rebalanced monthly by a periodic strategy, four threshold strategies and the Six Sigma strategy, or not rebalanced at all (the buy-and-hold strategy). Having the portfolios evaluated with respect to different measures of performance, it is found that the Six Sigma rebalancing strategy is the best performer when gross returns (not including transaction costs) and that the buy and hold strategy is superior in terms of net returns (including transaction costs). When drawn into comparison with the performance of the benchmark S\&P 500, the buy-and hold strategy is dominant with the Six Sigma strategy running up tightly. The least favourable is the simple periodic rebalancing that is used prevalently in the investment community.

The remainder of the paper is organized into four more sections. The next section makes a short literature review and is followed by a methodology section. This section describes general aspects of stock pre-selection and portfolio tracking and provides a description of rebalancing strategies, putting more emphasis upon the Six Sigma rebalancing strategy. The other two sections describe the set-up of the case study and present the results. The last section concludes and discusses.

\section{Literature Review}

The main benefit of rebalancing, when compared to the buy-and-hold strategy, is that it reduces risk substantially without any damage to mean returns that tend to remain on the same level or 
increase by a slight margin (see Dichtl et al., 2016). Both Bouchey et al. (2012) and Willenbrock (2011) recommend rebalancing as a means of keeping the portfolio diversified over the investment periods. Nonetheless, rebalancing need not be cheap as it increases transaction costs that push the net return of the investment down. This is especially in the case when portfolio revisions are implemented very often or the portfolio is composed of assets that trade at high liquidity costs. De Jong and Driessen (2013) established that in portfolio rebalancing $1 \%$ transaction costs can be off-set by earning an $0.2 \%$ extra annual return on a risky asset. There are two major groups of rebalancing strategies, i.e. period rebalancing and threshold rebalancing (e.g. Dichtl et al., 2016). Period rebalancing strategies are characterized by portfolio revisions implemented regularly over the investment horizon. The portfolio is revised periodically (e.g. on a monthly, quarterly, annual basis) regardless of whether the portfolio deviates from the benchmark significantly or whether these deviations are negligible. Threshold rebalancing strategies are also frequently put to use on a periodic basis (such as monthly, quarterly or annually), but the portfolio is revised according as it deviates significantly from the benchmark and a suitably defined discrepancy function passes a pre-specified threshold. Also the rebalancing strategy of Bod'a and Roháčová (2014) is a threshold rebalancing strategy that operates on Six Sigma ideas. Usefulness of rebalancing strategies was explored by Arnott and Lovell (1993), Plaxco and Arnott (2002), Tsai (2001) and Harjoto and Jones (2006). To a great extent, their findings offer mixed evidence. For instance, Arnott and Lovell (1993) recommend for long-term investments monthly periodic rebalancing. On the other hand, Plaxco and Arnott (2002) single out quarterly period rebalancing, whereas Tsai (2001) cannot not make a firm recommendation in favour of any rebalancing strategy. This author, however, fails to recognize transaction costs, which is also an issue with Harjoto and Jones (2006) who found that rebalancing is superior to non-rebalancing.

It seems that Six Sigma as a methodology has not been ushered in portfolio management. As was emphasized in the introduction, Bod'a and Roháčová (2014) were first to sketch an idea of rebalancing the portfolio on the basis of Six Sigma principles, and formulate it rigorously. Whilst no other SixSigma-based rebalancing strategy or any SixSigma-based portfolio selection method is known to the authors, there has already been a proposal to deploy Six Sigma in modelling financial risks. Doyle et al. (2010) discussed conceptually a fivestep process known in Six Sigma as DMAIC (Define/ Measure/Analyze/Improve/Control). Nonetheless, their descriptions were of a very vague and nonspecific nature, and they just communicated for the profession of risk management ideas borrowed in business management. A more advanced version is Mefford et al. (2017) who showed how the basic philosophy of Six Sigma to portfolio risk management and provided and empirical demonstration. The common denominator of the efforts borne by Doyle et al. (2010) and Mefford et al. (2017) is the deficiency of value at risk as the most popular method for measuring risk in finance.

\section{MATERIALS AND METHODS}

\section{Methodology}

The case study accomplished in the paper compares rebalancing strategies applied to tracking portfolios composed of stocks pre-selected and mixed from polar categories of the stock universe. The case study places an emphasis upon the Six Sigma rebalancing strategy proposed by Bod'a and Roháčová (2014) and confronts it with traditional rebalancing in several configurations, one of which then subsumes periodic rebalancing. Unsurprisingly, the notes on the methodological procedure must be devoted to the following topics: (a) balanced stock pre-selection based on polar investment styles, (b) portfolio tracking for portfolio selection, (c) the Six Sigma rebalancing strategy, and (d) traditional rebalancing strategies. This section covers these points.

\section{Stock Pre-selection and Portfolio Selection Based on Portfolio Tracking}

When a portfolio is to be created, some assets must be preferred over others and pre-selected. A preference for a certain class of assets is called an investment style. Pre-selection of stocks in the present study is based upon two classification criteria: screening on size and screening on multiples. The decision for using these two screening methods follows from the fact that stocks are mostly classified according to their market capitalization and value/growth potential into: (a) large size, (b) small size, (c) large value and small growth, (d) small value and large growth (see Fabozzi, 1998, p. 57). Big caps are usually safer (i.e. less volatile) than small caps. Hence, the size criterion of market capitalization may be deemed as associated with riskiness. As far as the growth/ value classification is concerned, growth stocks display promising growth prospects whereas low stocks are usually deemed as undervalued. This classification requires comparing market and book values of stocks, and thus it informs of (correct or inadequate) pricing.

Classical financial theory suggests that smaller firms are more risky than larger companies and this is the main point in explaining why small caps tend to earn better returns than big caps. Big caps ("B") are identified by ordering stocks by their market capitalization and selecting those above the 50\% quantile and the remaining stocks are classified as small caps (“S”). 
Classification into growth/value stocks stems from comparisons of the market values of stocks with the book values of fundaments that should be snapshots of performance. Investing into value stocks means purchasing stocks that are cheap relative to their fundaments and is based on the stylized fact that the market can be beaten by stocks that have prices low relative to their earnings, dividends, book values or other measures of their value. In step with common practice, the chosen reference fundamental here is equity and classification into growth/value stocks derives here from the $\mathrm{P} / \mathrm{B}$ (price-to-book) ratio. Stocks with high $\mathrm{P} / \mathrm{B}$ ratios are recognized as growth stocks ("G"), whereas stocks with low P/B ratios are singled out as value stocks ("V").

The tracking portfolios being created arise by investing a portion of the budget into big/small caps and the rest into growth/value stocks. The result is polar mixing portfolios: "BG”, "'BV", "SG” and "SV". For example, the tag "BG" appertains to tracking portfolios that put some proportion into big caps and the remainder is invested into growth stocks. Denote the proportions to be invested into "B"|"S" and "G"/"V" stocks as v and 1 - v, respectively. The same number $m$ of equities is chosen in each category and the weights in both classes of assets are determined separately. The same number $m$ of equities is chosen in each category and the weights in both classes of assets are determined separately. Denote the respective $(m \times 1)$ vectors of weights for "B" $/$ "S" and "G"/"V" stocks by $\mathrm{w}_{1}$ and $\mathrm{w}_{2}$. Both vectors are required to satisfy $\mathrm{w}_{1}{ }^{\prime} 1=1$ and $\mathrm{w}_{2}{ }^{\prime} 1=1$. Here 1 is an $(\mathrm{m} \times 1)$ vector of ones. The shares allocated into "“B")"S" and "G"/"V" stocks are then $\mathrm{V} \times \mathrm{w}_{1}$ and $(1-\mathrm{v}) \times \mathrm{w}_{2}$. The nominal portfolio size is $n=2 \mathrm{~m}$ since the portfolio is to be composed of m "B"/"S" and $m$ "G"/"V" stocks whenever a non-trivial case $\mathrm{V} \in(0,1)$ occurs. To ensure comparability and hold the portfolio nominal size intact, in the trivial case $\mathrm{v} \in\{0,1\} \mathrm{n}$ is reset to $2 \mathrm{~m}$. Throughout this process, the weights $\mathrm{w}_{1}$ and $\mathrm{w}_{2}$ are optimized independently using the formulation of quadratic tracking for the $\mathrm{m}$ "B"/"S" stocks and the m "G"/"V" stocks, respectively.

The task of portfolio tracking employs the quadratic formulation and presumes that a benchmark index is available. This function is fulfilled by the S\&P 500 Index as is clarified in the next section. The ambition of portfolio selection in this case is therefore to choose such a portfolio that mimics (tracks) the performance patterns of the S\&P 500 Index. The said tracking property is enforced by dint of the requirement that portfolio returns are as close to S\&P 500 returns as possible. Historical returns are employed to this end in the hope that the tracking portfolio does not deviate from the benchmark S\&P 500 Index over the investment horizon (which happens, and thus portfolio rebalancing aims at preventing the tracking portfolio from significant deviations by implementing portfolio revisions).
As was highlighted in the preceding paragraph, the optimization of portfolio tracking ran independently for each category of stocks $\mathrm{d}$, such that $d \in\{1,2\}$ with $d=1$ for "B""s" stocks and with $\mathrm{d}=2$ for "G"/"V" stocks. The weights for $\mathrm{m}$ stocks in category $\mathrm{d}, \mathrm{w}_{\mathrm{d}}=\left(\mathrm{w}_{\mathrm{d}, 1}, \ldots, \mathrm{w}_{\mathrm{d}, \mathrm{m}}\right)^{\prime}$, were identified by solving the following optimization program:

$\min _{\mathrm{w}_{\mathrm{d}} \in \Re^{\mathrm{m}}} \sum_{\mathrm{t}=1}^{\mathrm{t}=\mathrm{M}}\left(\mathrm{r}_{\mathrm{B}, \mathrm{t}}-\sum_{\mathrm{h}=1}^{\mathrm{h}=\mathrm{m}} \mathrm{W}_{\mathrm{d}, \mathrm{h}} \mathrm{r}_{\mathrm{h}, \mathrm{t}}\right)^{2}$

s.t. $\sum_{\mathrm{h}=1}^{\mathrm{h}=\mathrm{m}} \mathrm{w}_{\mathrm{d}, \mathrm{h}}=1, \mathrm{w}_{\mathrm{d}, \mathrm{h}} \geq 0$ for $\mathrm{h} \in\{1, \ldots, \mathrm{m}\}$,

which builds on a history of $\mathrm{M}$ benchmark returns $r_{B .1}, \ldots, r_{B . M}$ and on a history of $M$ returns $r_{h .1}, \ldots, r_{h . M}$ for the component assets $h \in\{1, \ldots, m\}$. The program seeks to define the tracking portfolio as a linear convex combination of $m$ assets so that the discrepancy between the tracking portfolio returns and the benchmark returns measured in terms of square errors is historically minimum. The convexity is ensured through consideration of only weighted averages (the unit sum constraint) with positive weights (the non-negativity constraint). The latter arises when short sales are disallowed. More details are provided e.g. by Bod'a and Kanderová (2018, pp. 1420). The model of computing portfolio holdings and calculating transaction costs is detailed in Bod'a and Kanderová 2018, pp. 1420-1421). A grave simplification associated with this model in comparison to practical conditions is that it overlooks the transaction costs that must be paid at revision times and that decrease the value of the portfolio. Somewhat simplistically it is assumed here that there exists a separate account that covers these transaction costs. Only the final value of the tracking portfolio is confronted with the volume of transaction costs (in an inflation-free world), and the net value of the investment is computed by subtracting the transaction costs total from the portfolio value.

\section{Six Sigma Rebalancing Strategy}

Six Sigma finds manifold application in the manufacturing and service industries, and in such a case the ultimate aim of Six Sigma is to eliminate defects and waste by measuring and reducing variations. Toward this end, any results of a process that fails to meet the preset expectations are considered as a defect. Six Sigma is a popular managerial approach to secure higher quality through which it should act upon higher revenues and lower costs. Its real-world applications and reception with the business community prove its potential, if applied correctly, to contribute substantially to cost reduction and time saving. Two basic interpretations are usually pointed out for Six Sigma (Kwak and Anbari, 2006; Bañuelas et al., 2005, p. 553). One interpretation is that it is a business strategy that requires full subordination of the philosophy, planning and operational management 
of an organization to the goal of reducing variability in business processes and eliminating waste that arise therewith. Another interpretation is associated with a quantitative methodology used in ensuring quality as it represents a set of statistical tools aiming to control and reduce variation about the process target or expected value. The term "sigma" originates from statistical terminology and represents standard deviation as a measure of this.

The traditional application of Six Sigma is based on the setting that the business process could be characterized by certain indicators (i.e. numeric variables) of its quality. It is sort of a stylized fact that many quality indicators are (just as they are or after a transformation) centred symmetrically about the target value and the results become more unlikely as their distance increases to one or another side. In effect, quality indicator in Six Sigma is assumed to be Gaussian $N\left(\mu, \sigma^{2}\right)$ where $\sigma$ is the standard deviation of the quality indicator in hand and is used to express the degree of variability of the process around the target (mean) value $\mu$. Tolerable outcomes of the process are delimited by a lower and upper specification limits: LSL and USL, respectively. Every realization of the process whose quality indicator falls outside the range [LSL, USL] is qualified as defective. In Six Sigma, defective realizations are not first handled in terms of their magnitude, but especially controlled through their incidence. A popular measure of the incidence of defects is Defects per Million of Opportunities (dpmo), which is the average number of defects per unit observed during a period divided by the number of opportunities to make the outcomes of the process defective normalized to one million. Its formal definition is

dpmo $=$

$$
=\frac{\# \text { defects }}{\# \text { units } \times \text { \# opportunities per unit }} \times 1,000,000 \text {. }
$$

Six Sigma requires that $99.999998 \%$ of all realizations of the process are good and fit within tolerance levels, which under Gaussianity implies that no more than 3.4 actual defects should occur per million opportunities, which is the level of dpmo that is striven to be maintained by Six Sigma. This number 3.4 follows from three ingredients: (1) it is desired that approximately $99.999998 \%$ of realizations of the process squeeze in the interval $\mu \pm 6 \sigma$, (2) there is a possible shift of 1.5 times standard deviation $\sigma$ to the right or left of the target value $\mu$, (3) the number of defect is expressed per million opportunities. The second element emanates from an observation that processes usually do not perform as well in the long horizon as they do in the short term. Empirical investigations show that processes tend to deviate from the target values (due to fatigue of material, machine wear, changing external conditions etc.) roughly by $1.5 \sigma$, which appears in the background calculations.
Considering this 1.5 sigma shift of mean in time, the empirical probability of defects may follows from the formula

$\Phi(-\Delta-1.5)+(1-\Phi(\Delta-1.5))=\frac{d p m o}{1,000,000}$

where $\Delta$ denotes the unknown sigma level of the process. It is clear that for the interval $\mu \pm 6 \sigma, \Delta$ is equal to 6, i.e. the Six Sigma level is achieved. Processes with higher sigma level have lower probabilities of defect causing dissatisfaction or failure of the specified requirements (for more details see e.g. Montgomery, 2001). The concept of Six Sigma is in more depth described by e.g. Schroeder et al. (2008) or $\mathrm{Zu}$ et al. (2008).

On application of Six Sigma ideas to financial investing at the capital market, quality must needs be understood in terms of the return-risk characteristics of the investment. Consistent with his risk profile, the investor has some desiderata about the performance of his portfolio and there is a defect whenever this performance fails to meet them. Generally, this happens when the (mean) return of the portfolio sinks below the target (minimum acceptable) return or when its volatility surpasses the target (maximum acceptable) level of risk. In passive investment, a benchmark embodies fully the risk profile of the investor since the benchmark's performance (return and risk) are such that are tolerable to the investor. According as the portfolio return chances to deviate (significantly) form the benchmark return, the investment process suffers from a failure and a defect arises. This is the bare idea embraced by Bod'a and Roháčová (2014) in formulating their rebalancing strategy that otherwise suits the needs of a passive investor with a well-define market benchmark. In their rebalancing strategy, sigma levels are calculated for the portfolio held over the investment horizon and act as an impetus for revising the portfolio composition. A decrease in the sigma level of the portfolio is taken as an impulse for intervention and changing its composition.

The following presentation of the rebalancing strategy of Bod'a and Roháčová (2014) presumes that a portfolio out of $n$ assets is already created with returns over a monitoring time frame $\mathrm{r}_{\mathrm{p} 1}, \ldots, \mathrm{r}_{\mathrm{pT}}$ and that this portfolio is matched against a benchmark with returns for this period $r_{B, 1}, \ldots, r_{B T}$ A case when the portfolio return is lower than the benchmark return is deemed as an undesirable incident, or a defect. The adopted interpretation is just onesided for a case when the portfolio return exceeds the benchmark return is in fact favourable to the investor albeit it may erode the risk dimension of his investment profile. For the period in question, there are $\mathrm{T}$ time instances when such a comparison is effected (and a defect can be observed), and a total of $n+1$ opportunities for defect per time instance. The number of opportunities that 
give rise to a defect is derived from the fact the outcome (conclusion) of the comparison $\mathrm{r}_{\mathrm{P}, \mathrm{t}}<\mathrm{r}_{\mathrm{B}, \mathrm{t}}$ for any $t \in\{1, \ldots, \mathrm{T}\}$ depends on the $\mathrm{n}$ assets and 1 benchmark. Therefore, the formula for dpmo is in this situation governed by the expression:

dpmo $=\frac{\#\left\{\mathrm{r}_{\mathrm{P}, \mathrm{t}}<\mathrm{r}_{\mathrm{B}, \mathrm{t}}\right\}}{\mathrm{T} \times(\mathrm{n}+1)} \times 1,000,000$.

Using formula (3), the calculated value of dpmo is convertible to the sigma level $\Delta$ of the portfolio.

Over the investment horizon, the situation in the market is likely to change and the history of returns over the most recent $\mathrm{T}$ time instances of the monitoring period must be updated. These new data with a data frame shifted by one, two etc. time instances may be then used to estimate the new value of dpmo and to determine the new value of sigma level. For $\tau$ time instances ahead and a consistent time frame of $\mathrm{T}$ time instances, the history of returns to be supplied into formula (4) is $r_{P, 1+\tau}, \ldots, r_{P, T+\tau}$ for the portfolio and $r_{B, 1+\tau}, \ldots, r_{B,+\tau}$ for the benchmark. If the new sigma level indicates a (substantial) decrease, this is suggestive that the quality of portfolio deteriorated over time and that a revision of its weights should be pondered over. In theory, it does not depend on the selection algorithm employed in the identification of weights providing that the portfolio is sought to remain consistent to the (mean) return and risk of the benchmark. Nevertheless, one possible scenario is that the new weights may not be apposite as they may in fact induce a deterioration of the sigma level. If the new weights should imply a lower (less acceptable) sigma level than the sigma level prior to the update, no update of the portfolio composition should be implemented and the portfolio should be kept unaltered.

The rebalancing strategy of Bod'a and Roháčová (2014) can be summarized in the following algorithm, in which Step 0 is portfolio construction and Steps 1 to 3 are portfolio rebalancing:

0 . Using a history of $\mathrm{T}$ equally-distant historical observations, optimize the portfolio and select its weights $\mathrm{w}_{1,0}, \ldots, \mathrm{w}_{\mathrm{n}, 0}$ (so that it is compliant with the benchmark). Calculate its initial sigma level $\Delta_{0}$. Go to Step 1.

Hold the length of the time frame $\mathrm{T}$ and the frequency of time instances unaltered and consistent with Step 0 , and for each $\tau \in\{1, \ldots, \mathrm{K}\}$ of the next $\mathrm{K}$ instances of the investment horizon repeat the following loop:

1. Update the history by shifting the time frame by one time instance and compute a new sigma level $\Delta_{\tau}$ with respect of this new information on the market situation. Go to Step 2.

2. Compare the new sigma level $\Delta_{\tau}$ and the previous sigma level $\Delta_{\tau-1}$.

a. If the new sigma level is not worse than the initial sigma level, $\Delta_{\tau} \geq \Delta_{\tau-1}$, then the portfolio stays non-rebalanced and the weights carry over so that $\mathrm{w}_{1, \tau} \equiv \mathrm{w}_{1, \tau-1}, \ldots, \mathrm{w}_{\mathrm{n}, \tau} \equiv \mathrm{w}_{\mathrm{n}, \tau-1}$. Move to the next period and update $\tau \equiv \tau+1$. Go to Step 1.

b. If the new sigma is lower than the old sigma level, $\Delta_{\tau}<\Delta_{\tau-1}$, the portfolio must be rebalanced and optimized anew, but there is no warranty that the optimized portfolio will be preferable in terms of the Six Sigma criterion. For the newly optimized set of weights $\mathrm{w}_{1, \tau}, \ldots, \mathrm{w}_{\mathrm{n}, \tau}$ \# compute a rebalanced sigma level $\Delta_{\tau}^{\#}$. Go to Step 3.

3. Compare the rebalanced sigma level $\Delta_{\tau}^{\#}$ and the new sigma level $\Delta_{\tau}$.

a. If the rebalanced sigma level at the reoptimized weights is not worse than the new sigma level at the old weights, $\Delta_{\tau}^{\#} \geq \Delta_{\tau}$, then switch to the rebalanced portfolio and reset the weights to $\mathrm{w}_{1, \tau} \equiv \mathrm{W}_{1, \tau}$, $, \ldots, \mathrm{W}_{\mathrm{n}, \tau} \equiv \mathrm{w}_{\mathrm{n}, \tau}$. . Move to the next period and update $\tau \equiv \tau+1$. Go to Step 1.

b. If the rebalanced sigma level at the reoptimized weights is lower than the new sigma level at the old weights, $\Delta_{\tau}^{\#}<\Delta_{\tau}$, no rebalancing is performed and the portfolio composition remains unchanged with weights $\mathrm{W}_{1, \tau} \equiv \mathrm{W}_{1,-1}, \ldots, \mathrm{W}_{\mathrm{n \tau}} \equiv \mathrm{W}_{\mathrm{n} \tau-1}$. Move to the next period and update $\tau \equiv \tau+1$.

\section{Traditional Intervention Rebalancing Strategies}

Traditionally rebalancing is implemented at evenly-spaced time instances either regularly no matter what the market development is (periodic rebalancing) or conditionally only if the market development is unfavourable (deviation rebalancing). In both approaches, the portfolio is constantly checked over the investment horizon on a regular periodic basis (e.g. monthly, quarterly, semi-annually) and its performance reassessed. The difference is that under periodic rebalancing the portfolio is reoptimized without exception with regard to a new updated history of observations. The consequence is that the portfolio may be rebalanced even if there is no need and higher transaction costs ensue. In contrast, under deviation rebalancing, the portfolio is reoptimized only if the portfolio distances itself significantly from the desired return-risk profile of the investor. Toward this end, a tolerance threshold triggering an intervention action must be pre-determined and in the case of passive investing an intervention is undergone only if the portfolio deviates from its benchmark by more than the threshold. A problematic judgmental input is here the choice of threshold, but this approach is economical in transaction costs. It is obvious that whenever (trivially) a zero tolerance threshold is set, then deviation rebalancing transforms into periodic rebalancing. Of course, there are several options how a deviation of the portfolio from the 
benchmark may be handled and quantified. One possibility is to measure the difference between normalized values and returns of the portfolio and the benchmark. Another possibility is to examine the difference between the weights optimized and applied at the inception of the portfolio and the newly optimized weights that reflect new market developments. The latter approach is adopted here.

Formally, suppose that a tolerance threshold applicable to weights have been set $\theta$ such that $\theta \in[0,1)$. A deviation rebalancing strategy operating at weights works in the sequence of the following steps, in which Step 0 is portfolio construction and Steps 1 to 3 are portfolio rebalancing:

0 . Using a history of $\mathrm{T}$ equally-distant historical observations, optimize the portfolio and select its weights $\mathrm{w}_{1,0}, \ldots, \mathrm{W}_{\mathrm{n}, 0}$ (so that it is compliant with the benchmark). Go to Step 1.

Hold the length of the time frame $\mathrm{T}$ and the frequency of time instances unaltered and consistent with Step 0, and for each $\tau \in\{1, \ldots, K\}$ of the next $\mathrm{K}$ instances of the investment horizon repeat the following loop:

1. Update the history by shifting the time frame by one time instance and compute the marketdriven composition of the portfolio given current market prices. The result is a set of current portfolio weights $\mathrm{W}_{1, \tau}{ }^{\mathrm{c}}, \ldots, \mathrm{W}_{\mathrm{n}, \tau}{ }^{\mathrm{c}}$. Go to Step 2.

2. Compare the current market weights $\mathrm{w}_{1, \tau}{ }^{\mathrm{c}}, \ldots, \mathrm{w}_{\mathrm{n}, \tau}{ }^{\mathrm{c}}$ and the previous weights $\mathrm{W}_{1, \tau-1}, \ldots, \mathrm{W}_{\mathrm{n}, \tau-1}$.

a. If any of the weights deviate by more than the threshold, i.e. $\exists \mathrm{i}:\left|\mathrm{w}_{\mathrm{i}, \tau}{ }^{\mathrm{c}}-\mathrm{w}_{\mathrm{i}, \tau-1}\right|>\theta$ for $i \in\{1, \ldots, n\}$, the portfolio must be rebalanced. The portfolio is then reoptimized and a new set of weights identified $\mathrm{W}_{1, \tau}{ }^{\#}, \ldots, \mathrm{W}_{\mathrm{n}, \tau}^{\#}$. Eventually, the weights are reset to $\mathrm{W}_{1, \tau} \equiv \mathrm{W}_{1, \tau}{ }^{\#}, \ldots, \mathrm{W}_{\mathrm{n}, \tau} \equiv \mathrm{W}_{\mathrm{n}, \tau}^{\#}$. Move to the next period and update $\tau \equiv \tau+1$. Go to Step 1 .

b. If there is no significant deviation between the sets of weights, i.e. $\forall \mathrm{i}:\left|\mathrm{w}_{\mathrm{i}, \tau}{ }^{\mathrm{c}}-\mathrm{w}_{\mathrm{i}, \tau-1}\right| \leq \theta$ with $i \in\{1, \ldots, n\}$, then there is no rebalancing at all and the weights remain unaltered with $\mathrm{W}_{1, \tau} \equiv \mathrm{W}_{1, \tau-1}, \ldots, \mathrm{W}_{\mathrm{n}, \tau} \equiv \mathrm{W}_{\mathrm{n}, \tau-1}$. Move to the next period and update $\tau \equiv \tau+1$. Go to Step 1 .

It is obvious that periodic rebalancing arises when $\theta \equiv 0$, in which case there always is some rebalancing.

\section{Data}

In line with the experience in earlier studies of the sort (e.g. Bod'a and Kanderová, 2018), the case study is built around a small investor whose benchmark is the S\&P 500 Index and who intends to invest into its components in an attempt to track it. The choice fell upon the S\&P 500 because it is a good informal descriptor of the US stock market and belongs to the most widely quoted American indices. As it includes the largest publicly traded corporations in the U.S., it is obviously capable of picking up general market trends. The components of the S\&P 500 are suitable for a small non-institutionalized investor as they are instantly tradable without liquidity costs. For a small investor transaction costs are a substantial part of his entire performance so in order to have them under control, he is prepared to invest to 40 stocks at most. He uses data of monthly frequency: a history of 24 monthly logarithmic returns covering two years (the in-sample period) is employed in portfolio selection and the portfolio is monitored for the next two years (the out-ofsample period) at regular monthly intervals and, if necessary, rebalanced. Every time portfolio composition is sought, the method of quadratic tracking is employed with the S\&P 500 fulfilling the role of benchmark. Likewise, every time, the portfolio composition is changed, transaction costs are incurred.

As many as four samples were created to aid higher generalizability and to suppress market trends to some degree. These samples (referred to later as "periods") spanned a period of four years, with the first two years representing the in-sample period of 24 monthly returns for portfolio selection and the last two years standing for the out-ofsample horizon of active investing and rebalancing. The samples started at 2011 (the start of the first in-sample period) and ended at 2017 (the end of the fourth out-of-sample period). These samples are denoted in what follows as "20112014" to “20142017”.

The constituents of the S\&P 500 with a full history of available data for the entire four-year period were divided by market capitalization into "B"/"S" stocks and by the P/B ratio into "G"/"V" stocks. The classification was performed in consistency with the notes made in the previous section. The effective number of S\&P 500 stocks was somewhat smaller than the traditional approximate 500 stocks as a result of changes in the index, withdrawals from public trading or mergers and acquisitions. Hence, the effective basket of the S\&P 500 constituents varied accordingly with periods: 450 (with period “20122015”), 457 (with period “20132016”), 458 (with periods "20112014" and "20142017”).

A concise statistical description of the four periods is displayed in Tab. I. The table compiles mean returns and volatilities (expressed as annual percentages) of the S\&P 500 and its constituents in the categories of "B", "S", "G", and "V" stocks. For the four categories of stocks, average mean returns and average volatilities are reported as rough and crude indicators of performance of the stocks in these categories. Some differences and regular patterns are suggested by Tab. I for the in-sample and out-of-sample periods of the four samples included in the analysis. These regularities testify that the samples are in a certain aspect balanced for the case study of this paper concerning market 
I: Statistics of the data sets

\begin{tabular}{|c|c|c|c|c|c|c|c|c|c|c|}
\hline \multirow[b]{2}{*}{ Sample } & \multicolumn{2}{|c|}{ S\&P 500} & \multicolumn{2}{|c|}{ Big caps (“B”) } & \multicolumn{2}{|c|}{ Small caps (“S") } & \multicolumn{2}{|c|}{ Growth stocks ("G”) } & \multicolumn{2}{|c|}{ Value stocks ("V") } \\
\hline & $\begin{array}{l}\text { Mean } \\
\text { return }\end{array}$ & Volatility & $\begin{array}{l}\text { Mean } \\
\text { returns }\end{array}$ & $\begin{array}{l}\text { Average } \\
\text { volatility }\end{array}$ & $\begin{array}{l}\text { Mean } \\
\text { returns }\end{array}$ & $\begin{array}{l}\text { Average } \\
\text { volatility }\end{array}$ & $\begin{array}{c}\text { Mean } \\
\text { returns }\end{array}$ & $\begin{array}{c}\text { Average } \\
\text { volatility }\end{array}$ & $\begin{array}{l}\text { Mean } \\
\text { returns }\end{array}$ & $\begin{array}{c}\text { Average } \\
\text { volatility }\end{array}$ \\
\hline \multicolumn{11}{|c|}{ Period 20112014} \\
\hline Full & $12.32 \%$ & $11.13 \%$ & $12.19 \%$ & $21.29 \%$ & $9.71 \%$ & $29.12 \%$ & $14.14 \%$ & $25.48 \%$ & $8.28 \%$ & $24.68 \%$ \\
\hline InS & $6.29 \%$ & $13.28 \%$ & $7.05 \%$ & $23.51 \%$ & $1.52 \%$ & $29.39 \%$ & $10.09 \%$ & $25.25 \%$ & $-0.52 \%$ & $27.27 \%$ \\
\hline Outs & $18.36 \%$ & $8.39 \%$ & $17.32 \%$ & $18.17 \%$ & $17.90 \%$ & $26.41 \%$ & $18.19 \%$ & $23.50 \%$ & $17.09 \%$ & $20.94 \%$ \\
\hline \multicolumn{11}{|c|}{ Period 20122015} \\
\hline Full & $12.14 \%$ & $10.43 \%$ & $11.89 \%$ & $21.13 \%$ & $8.12 \%$ & $25.30 \%$ & $12.81 \%$ & $22.97 \%$ & $7.57 \%$ & $23.31 \%$ \\
\hline InS & $19.25 \%$ & $9.60 \%$ & $22.97 \%$ & $20.12 \%$ & $18.57 \%$ & $23.41 \%$ & $23.34 \%$ & $21.31 \%$ & $18.58 \%$ & $22.08 \%$ \\
\hline Outs & $5.03 \%$ & $11.02 \%$ & $0.80 \%$ & $21.33 \%$ & $-2.34 \%$ & $25.93 \%$ & $2.28 \%$ & $23.49 \%$ & $-3.43 \%$ & $23.62 \%$ \\
\hline \multicolumn{11}{|c|}{ Period 20132016} \\
\hline Full & $11.27 \%$ & $10.32 \%$ & $11.78 \%$ & $22.02 \%$ & $8.13 \%$ & $26.25 \%$ & $11.74 \%$ & $23.41 \%$ & $8.48 \%$ & $24.61 \%$ \\
\hline InS & $18.36 \%$ & $8.39 \%$ & $21.83 \%$ & $18.59 \%$ & $16.13 \%$ & $21.85 \%$ & $22.17 \%$ & $19.75 \%$ & $16.31 \%$ & $20.50 \%$ \\
\hline Outs & $4.19 \%$ & $11.77 \%$ & $1.74 \%$ & $24.35 \%$ & $0.13 \%$ & $29.40 \%$ & $1.32 \%$ & $25.86 \%$ & $0.65 \%$ & $27.58 \%$ \\
\hline \multicolumn{11}{|c|}{ Period 20142017} \\
\hline Full & $9.23 \%$ & $9.48 \%$ & $10.21 \%$ & $21.24 \%$ & $2.22 \%$ & $26.27 \%$ & $10.05 \%$ & $22.81 \%$ & $3.33 \%$ & $24.39 \%$ \\
\hline InS & $5.03 \%$ & $11.02 \%$ & $8.59 \%$ & $21.28 \%$ & $-4.17 \%$ & $24.52 \%$ & $9.40 \%$ & $22.42 \%$ & $-3.25 \%$ & $23.20 \%$ \\
\hline OutS & $13.43 \%$ & $7.70 \%$ & $11.83 \%$ & $20.49 \%$ & $8.60 \%$ & $27.07 \%$ & $10.70 \%$ & $22.27 \%$ & $9.91 \%$ & $24.83 \%$ \\
\hline
\end{tabular}

Legend: "Full" represents the full period in question (including both the in-sample and out-of-sample period), whereas "InS" stands for the in-sample period and "OutS" for the out-of sample period.

Note: Whilst for the S\&P 500 Index "mean return" and "volatility" were computed in a regular manner and their meaning is standard, for the four categories of S\&P 500 stocks "mean returns" and "average volatility" represent averages of the mean returns and volatilities of the stocks in that particular category.

conditions and trends. For period "20112014” the outof-sample period (the investment period) was actually preferable for investing than the in-sample period as it was typified by comparatively higher returns and lower risk. Almost an identical pattern of regularities was discovered for period "20142017" except that "S" and "G" stocks were on average riskier in the out-ofsample period. On the contrary, in periods " 20122015 " and "20132016" returns higher and smaller volatilities were in the in-sample period, which rendered the insample period preferable for an investment than the out-of-sample period. Remarkably, for the three last periods big stocks on average outperformed small caps, both in terms of return and risk, and for all the four periods growth stocks outperformed value stocks. These patterns are inconsistent with prevailing beliefs (e.g. Bauman et al., 1998; Doukas et al., 2002; Levis, 2002; Switzer, 2010). A possible explanation is that no adjustment for systemic risk was effected.

For each period typifying a particular investment situation, 4 nominal portfolio sizes and 20 mixing portfolios were created. The nominal portfolio sizes were 10, 20, 30 and 40 stocks, composed by halves of stocks belonging to different investment styles. Mixing portfolios arose by investing into "S" and "G" stocks ("SG" mixing portfolios), "S" and "V" stocks" ("SV" mixing portfolios), "B" and "G” stocks ("BG” mixing portfolios), and "B" and "V" stocks" ("BV" mixing portfolios). The mixing was controlled by weights $\mathrm{V} \in\{0.00,0.25,0.50,0.751 .00\}$. For example, for the weight 0.25 in the case of a 20-asset "SV" mixing portfolio, 25\% of the funds were allocated in 10 "S" stocks and 75\% into 10 "V" stocks. For the borderline weights 0.00 and 1.00, all of the funds were allocated into stocks of one investment style.

In portfolio tracking, the initial investment was made at the end of the in-sample period in the amount of US $\$ 10,000$. Shorts sales were not permitted as well and the rate of transaction costs was set to $0.4 \%$ (this choice is not unconventional, e.g. Ionescu, 2002, Grobys, 2010). This rate was applied to the amount of portfolio revisions, i.e. the monetary volume of purchases and the monetary volume of sales irrespective of the sign.

The matrix format of the case study "period $4 \times 4 \times 20=320$ portfolios to which 7 rebalancing strategies were applied over the outof-sample period tantamount with an investment horizon

- The buy-and-hold rebalancing strategy (no rebalancing), in which no revision is introduced into the portfolio composition over the whole outof-sample period. The portfolios selected at the end of the in-sample period remained intact. 
- The Six Sigma rebalancing strategy of Bod'a and Roháčová (2014), under which the portfolios were monitored periodically at regular monthly intervals over the out-of-sample period and whenever their sigma level worsened, they were rebalanced.

- Five deviation rebalancing strategies, in which the portfolios were monitored at a monthly frequency and revisions were effected only when their actual market weights answering to current prices deviated significantly from the initially optimized weights by a threshold $\theta$. The five thresholds specified here are $\theta \in\{0.0 \%, 1.5 \%, 3.0 \%$, $4.5 \%, 6.0 \%$ \}. Note that the first threshold $\theta=0.0 \%$ virtually transforms deviation rebalancing into a monthly periodic rebalancing strategy.

The case study thus makes comparison for four rebalancing approaches: no rebalancing, Six Sigma rebalancing, deviation rebalancing and period rebalancing; all of them being on a monthly frequency. In addition, at the end of the out-of-sample period, the terminal value of the tracking portfolios was reduced by the amount of transaction costs arising at the inception and with rebalancing and their performance measured. That being said, the portfolios were not liquidated at the end of the out-ofsample period, but were left to carry over.

In sum, there were as many as 320 tracking portfolios constructed at the end of the in-sample periods using the formulation of quadratic tracking whose performance was further affected by the choice of one of 7 rebalancing strategies with a total of $320 \times 7=2,240$ outcomes. The performance was assessed in terms of

- mean return, volatility and their ratio over the out-of sample period (measures that do not include transaction costs),

- mean active return, active volatility and their ratio over the out-of-sample period (measures that do not include transactions costs, but contrast performance with the benchmark),

- net compound return accumulated during the out-of sample period (a measure that includes transaction costs).

All these indicators were transformed into annual percentages (for volatilities using the traditional square-root-of-time rule). Mean return and volatility measure the average (annualized) value of logarithmic tracking portfolio returns and their standard deviation over the entire out-of-sample period. Mean active return and active volatility accomplish this measurement using logarithmic returns in excess of logarithmic benchmark returns (here returns of the S\&P 500). Net cumulative return is the annual geometrically-compounded average return after the deduction of transaction costs that arose at the inception of the portfolio and owing to its rebalancing. Whilst return is a measure of appreciation and volatility is a measure of risk, their ratio as a variation of the reward-risk ratio measures performance.
In computations and preparing graphical presentations, the software $\mathrm{R}$ version 3.4.1 (R Core Team, 2017) was employed with several of its libraries, quantmod (Ryan et al., 2017), quadprog (Turlach and Weingessel, 2013), timeseries (Wuertz and Chalabi, 2013) and PerformanceAnalytics (Peterson et al., 2014).

\section{RESULTS}

The case study generated an extensive output that is available from the authors on request. One portion of the results, in somewhat condensed form, is in the Appendix. It relates to the performance of the tracking portfolios that arose from investing into stocks on the basis of a unipolar investing style, i.e. for situations when an extreme choice for the weight was made and $\mathrm{V} \in\{0.00,1.00\}$. In such a case, all investment was made into "B", "S", "G" or "V" stocks. Condensation means here that the numbers reported in the table are only averages for the portfolios made up of 10 , 20, 30 and 40 stocks. Honestly, some part of the information is lost by taking averages, but the tables in Appendix sketch a rough assessment. Of evident importance is an enumeration of the rebalancing strategies found superior in individual configurations "period $\times$ portfolio size $\times$ mixing" as well as information by how much the Six Sigma rebalancing strategy outperformed or underperformed other rebalancing strategies. The former interest is satisfied in compacted form by Tabs. II and III and the latter inquiry is addressed by Fig. 1.

Tab. II shows frequencies with which rebalancing strategies were found superior with respect to 7 different evaluation criteria. As many as 320 tracking portfolios were fictively created in the case study and for each portfolio one or more rebalancing strategies appeared equally most favourable. For some portfolios, all the rebalancing strategies considered yielded no satisfactory result (which occurs with a negative mean return, a negative active return and a negative net compound return), which is reported in line "All unacceptable". Many times some strategies yielded an identical preferable performance result, for which reason they are grouped in the same line of Tab. II. Since Tab. II is to some degree uninformative, Tab. III disentangles co-occurrences of identical best performance shared by various rebalancing strategies, and reports how many times a rebalancing strategy appeared most favourable. The difference between Tabs. II and III is that Tab. II makes overview for the 320 tracking portfolios, whereas Tab. III does this for the 7 rebalancing strategies. Of course, for semantic reasons now "All unacceptable" goes into "None at all" with the same meaning.

The results organized in Tabs. II and III evince that it is very difficult to outperform the S\&P 500 no 
II: Overview of superior rebalancing strategies

\begin{tabular}{|c|c|c|c|c|c|c|c|}
\hline \multirow{3}{*}{$\begin{array}{l}\text { Best rebalancing } \\
\text { strategies }\end{array}$} & \multicolumn{7}{|c|}{ Number of cases } \\
\hline & Mean return & Volatility & Performance & $\begin{array}{l}\text { Mean active } \\
\text { return }\end{array}$ & $\begin{array}{c}\text { Active } \\
\text { volatility }\end{array}$ & $\begin{array}{c}\text { Active } \\
\text { performance }\end{array}$ & $\begin{array}{c}\text { Net } \\
\text { compound }\end{array}$ \\
\hline & [Ret] & [Vol] & Ret/Vol & [ARet] & [AVol] & ARet/AVol & return \\
\hline All unacceptable & 13 & 0 & 13 & 211 & 0 & 211 & 15 \\
\hline $\mathrm{BH}$ & 19 & 18 & 21 & 12 & 22 & 12 & 22 \\
\hline $\mathrm{BH} D\{0.030-0.060\}$ & 0 & 15 & 1 & 0 & 15 & 0 & 6 \\
\hline BH D $\{0.045-0.060\}$ & 25 & 28 & 29 & 9 & 25 & 10 & 42 \\
\hline BH D0.060 & 13 & 13 & 17 & 5 & 21 & 5 & 18 \\
\hline BH SS & 4 & 0 & 2 & 4 & 2 & 4 & 4 \\
\hline BH SS D $\{0.030-0.060\}$ & 0 & 1 & 1 & 0 & 1 & 0 & 0 \\
\hline BH SS D $\{0.045-0.060\}$ & 0 & 1 & 1 & 0 & 2 & 0 & 1 \\
\hline $\mathrm{D}\{0.045-0.060\}$ & 3 & 0 & 3 & 0 & 0 & 0 & 3 \\
\hline D0.000 & 35 & 19 & 28 & 11 & 22 & 11 & 16 \\
\hline D0.015 & 48 & 86 & 44 & 21 & 69 & 21 & 44 \\
\hline D0.030 & 41 & 35 & 50 & 10 & 39 & 10 & 39 \\
\hline D0.045 & 19 & 26 & 16 & 6 & 23 & 6 & 21 \\
\hline D0.060 & 13 & 6 & 9 & 7 & 6 & 7 & 14 \\
\hline SS & 87 & 72 & 85 & 24 & 73 & 23 & 75 \\
\hline Total number of cases & 320 & 320 & 320 & 320 & 320 & 320 & 320 \\
\hline
\end{tabular}

Legend: "BH" stands for the buy-and-hold strategy, "D" denotes a deviation rebalancing strategy with the choice of treshold that is appended on the right side either as a particular value or a range of values, "SS" is the Six Sigma rebalancing strategy.

Note: "D0.000" coincides with periodic rebalancing.

III: Incidence of superior rebalancing strategies with acceptable outcomes

\begin{tabular}{|c|c|c|c|c|c|c|c|}
\hline \multirow{3}{*}{ Rebalancing strategy } & \multicolumn{7}{|c|}{ Number of cases } \\
\hline & Mean return & Volatility & Performance & $\begin{array}{l}\text { Mean active } \\
\text { return }\end{array}$ & $\begin{array}{c}\text { Active } \\
\text { volatility }\end{array}$ & $\begin{array}{c}\text { Active } \\
\text { performance }\end{array}$ & \multirow{2}{*}{$\begin{array}{l}\text { Net } \\
\text { return }\end{array}$} \\
\hline & [Ret] & [Vol] & Ret/Vol & [ARet] & [AVol] & ARet/AVol & \\
\hline None at all & 13 & 0 & 13 & 211 & 0 & 211 & 15 \\
\hline $\mathrm{BH}$ & 61 & 76 & 72 & 30 & 88 & 31 & 93 \\
\hline D0.000 & 35 & 0 & 2 & 4 & 2 & 4 & 4 \\
\hline D0.015 & 48 & 86 & 44 & 21 & 69 & 21 & 44 \\
\hline D0.030 & 41 & 51 & 52 & 10 & 55 & 10 & 45 \\
\hline D0.045 & 47 & 71 & 51 & 15 & 66 & 16 & 73 \\
\hline D0.060 & 54 & 64 & 61 & 21 & 70 & 22 & 84 \\
\hline SS & 91 & 74 & 89 & 28 & 78 & 27 & 80 \\
\hline
\end{tabular}

Legend: "BH" stands for the buy-and-hold strategy, "D" denotes a deviation rebalancing strategy with the choice of treshold that is appended on the right side, "SS" is the Six Sigma rebalancing strategy.

Note: "D0.000" coincides with periodic rebalancing.

matter whether rebalancing is performed, or not. This is evident for most of the tracking portfolios (211 out of 320) where the outcomes were unacceptable relative to the S\&P 500 as their mean active returns were negative. In these cases neither buy-and-hold nor rebalancing appear particularly helpful. Nonetheless, rebalancing does improve upon the buy-and-hold strategy in achieving higher mean return (and performance in general) when no comparison to the index is made, but this advantage 

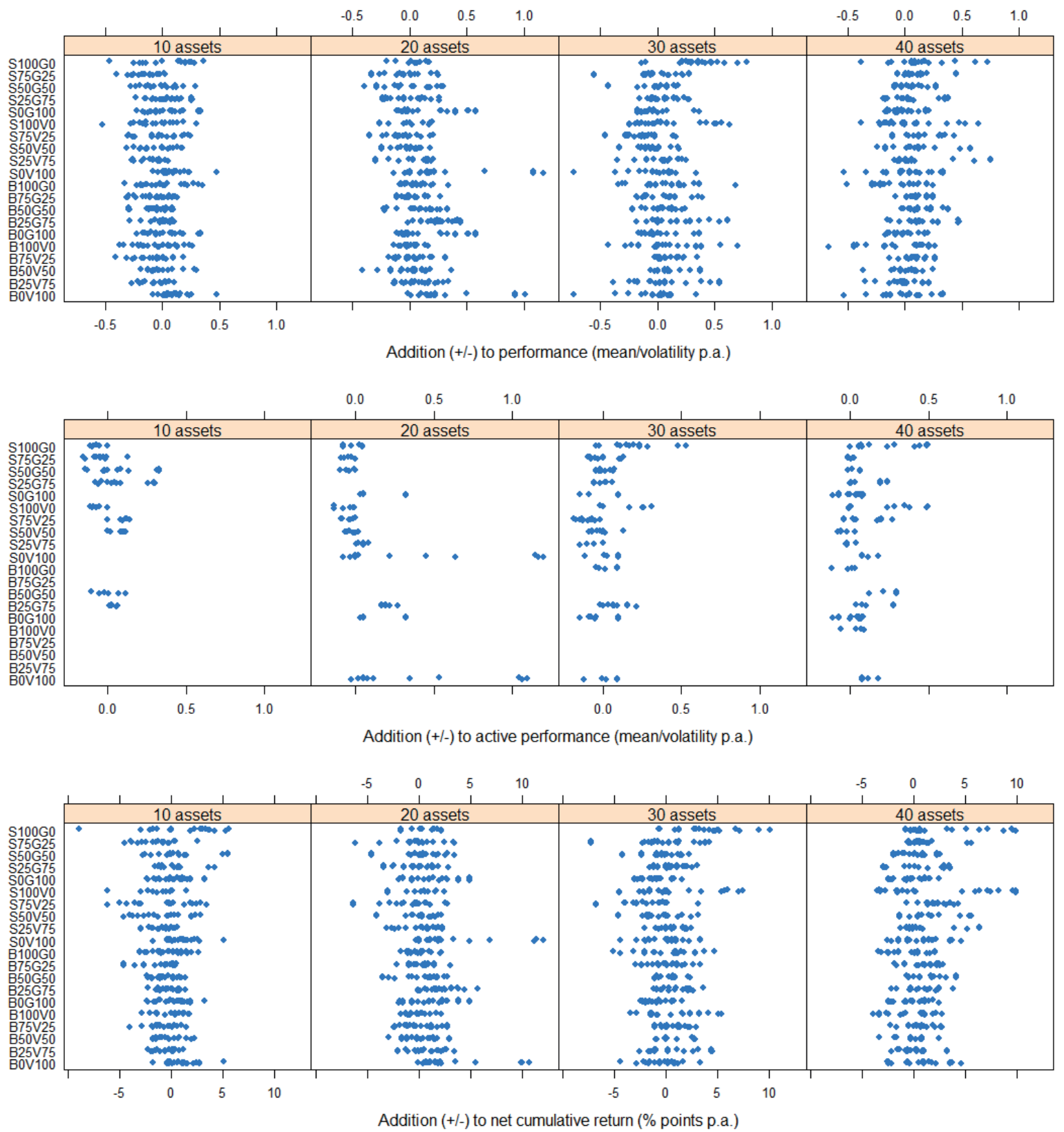

1: Surpluses of Six Sigma rebalancing over the other strategies considered

is severely downplayed when transaction costs are taken into account. In greater detail, the following few patterns may be read from Tabs. II and III:

Six Sigma rebalancing as proposed by Bod'a and Roháčová (2014) is most promising when the investment results are drawn into comparison with neither the index nor transaction costs. Tracking portfolios attained the best mean returns and performance (measured by the mean-return-tovolatility ratio) with Six Sigma rebalancing, which surpassed the buy-and-hold strategy and all the other rebalancing strategies. It dominated with 91 portfolios (with respect to mean return) and with 89 portfolios (with respect to the chosen ratio), and was followed by buy-and-hold with 61 portfolios (with respect to mean return) and 89 portfolios (with respect to the ratio). Nonetheless, the smallest volatilities were attained most frequently with the aid of deviation rebalancing at a modest choice of threshold $\theta=1.5 \%$ (86 tracking portfolios). This is suggestive that Six Sigma rebalancing may be most favourable in terms of return and overall performance, but deviation rebalancing with a properly selected threshold (which is a judgemental input) is contributive significantly to volatility reduction. The poorest performance is found with regular rebalancing (D0.000).

When the performance of the 320 tracking portfolios is matched against the performance of the S\&P 500, the tracking portfolios are mostly 
unsatisfactory and unable to meet the returngenerating capacity of the index. As many as 211 tracking portfolios wound up with negative mean active returns (and also mean-active-return-toactive-volatility ratios). In comparison to the S\&P 500, the most tracking portfolios with positive mean active returns as well as active performance ratios were obtained under no rebalancing at all, i.e. 30 and 31 portfolios respectively. The preference of buyand-hold goes just by a narrow margin as 28 and 27 portfolios were found most attractive under Six Sigma rebalancing. A suchlike pattern emerges with active volatility, which is smallest for 88 tracking portfolios under buy-and-hold, and then for 78 portfolios under Six Sigma rebalancing. The other rebalancing strategies showed comparatively worse results. Again, the poorest performance is yielded by regular rebalancing (D0.000).

Having transactions costs explicitly considered, Six Sigma rebalancing is the third favourable approach. The highest acceptable net compound return was attained most frequently with no rebalancing (93 tracking portfolios) and then with deviation rebalancing with a liberal value of threshold $\theta=6.0 \%$ (84 tracking) and finally with Six Sigma rebalancing (80 portfolios). As a rule, regular rebalancing was least favourable. The higher the threshold $\theta$, the less favourable performance in terms of net compound return. All the said patterns are understandable and natural given the fact that transaction costs push attractiveness of rebalancing down.

For the three comprehensive performance indicators - mean-return-to-volatility ratios, meanactive-return-to-active-volatility ratios and net compound return - Fig. 1 displays differences between Six sigma rebalancing and all the other strategies considered. For each tracking portfolio, the performance of Six Sigma rebalancing could be matched against the performance of the other six rebalancing approaches (BH, D0.000 to D0.006), in which Fig. 1 is a structured presentation of these boosts and slacks. The strip charts are drawn only for tracking portfolios for which tracking portfolios where there at least one rebalancing strategy gave an acceptable results (as explained earlier). Positive values are in favour of Six Sigma rebalancing, whereas negative values mean that Six Sigma rebalancing fared less satisfactorily. Codes on the vertical axis B0V100 to S100G0 label the mixing of tracking portfolios. For example, B25G75 identifies tracking portfolios emerging from investing into "B" and "G" stocks by 25\% and 75\%, respectively. It is discernible that for the first two performance measures positive values prevail, although for active performance that arises from comparisons with the S\&P 500 the strip charts give a sparse visual. In the case when transaction costs are fully accounted for, negative values dominate and Six Sigma rebalancing produces disbenefits to total return. What is apparent, yet not pursued as it is outside the current research interest, is that the strip charts give a wavelike pattern (except those for active performance, which is for reasons understandable). The benefits of Six Sigma rebalancing seem to manifest primarily in the case of unipolar investing when all funds are allocated into stock of one category and not mixed (such as small caps, big caps, growth stocks and value stocks).

\section{CONCLUSION}

Although the generalizability of results established by the current case study is somewhat limited as the research set-up appertains only to a U.S. stock market within a specific time frame and reposes upon a simple design of rebalancing, it proves that rebalancing on Six Sigma ideas might be beneficial to the investor. The Six Sigma rebalancing strategy proposed by Bod'a and Roháčová (2014) and verified in the case study is coarse in the sense that it does not optimize for transactions costs arising upon every intervention into portfolio composition. Nonetheless, it is ascertained that with no transaction costs Six Sigma rebalancing is generally superior over periodic and deviation rebalancing. The study shows that when performance is evaluated as such (without relation to the benchmark and regardless of transaction costs), Six Sigma rebalancing dominates and that when active performance is checked (with relation to the benchmark, though regardless of transaction costs), Six Sigma rebalancing is by a slight margin dominated by no rebalancing at all. It is somewhat surprising that albeit the purpose of rebalancing is to restore the return-risk characteristics desired by the investor and keep them preserved over the investment horizon, traditional rebalancing strategies are not found especially useful. To the benefit of the investor is found the dichotomy formed by no rebalancing and Six Sigma rebalancing. Nonetheless, as Six Sigma rebalancing leads to some changes in portfolio composition and induces transaction costs, which is sometimes more frequent that under deviation rebalancing with a lenient value of threshold, under the criterion of net compound return (without relation to the benchmark, but inclusive of transaction costs) the desirability of Six Sigma rebalancing is diminished to some extent.

Of course, an optimal rebalancing strategy does not exist and its choice or performance is highly individual. The strategy of no rebalancing will work perfectly under all scenarios and much depends on market trends and changes. Not even Six Sigma rebalancing, whether in this simple 
formulation or its refined version, will work equally well. Nonetheless, this case study demonstrates that Six Sigma rebalancing outperforms simpler designs such as periodic rebalancing and deviation rebalancing which do not improve convincingly on the buy-and-hold strategy. Furthermore, the design of the case study may be tailored to a small investor, but the conclusions are also valid to institutional investors. Certainly, the present findings are affected chiefly by two major specifications of the case study. One is the definition of the benchmark (the S\&P 500 Index) and of the universe of assets for portfolio selection (S\&P 500 constituents). The other is the choice of relatively more recent temporal periods consisting of two-year in-sample periods and two-year out-of-sample periods. To the contrary, reliance on monthly data is standard, and of marginal importance are the preference of quadratic tracking and the specified charge for transaction costs. Quadratic tracking is a robust approach to portfolio selection, whilst the chosen rate of transaction costs indicates liquid markets with frequent trades.

\section{Acknowledgements}

The research presented in the paper arose in fulfilment of the grant scheme of VEGA [\# 1/0554/16].

\section{REFERENCES}

ARNOTT, R. D. and LOVELL, R. M. 1993. Rebalancing: Why? When? How often? The Journal of Investing, 2(1): 5-10.

BAÑUELAS, R., ANTONY, J. and BRACE, M. 2005. An application of Six Sigma to reduce waste. Quality and Reliability Engineering International, 21(6): 553-570.

BAUMAN, W. S., CONVER, C. M. and MILLER, R. E. 1998. Growth versus value and large-cap versus small-cap stocks in international markets. Financial Analysts Journal, 54(2): 75-89.

BOĎA, M. and KANDEROVÁ, M. 2017. Selecting a small portfolio of equities: one-stop shopping approach to screening. In: Applications of Mathematics and Statistics in Economics 2017. Conference proceedings. Full-text papers. 30 Aug - 3 Sep: Szklarska Poręba. Wrocław: Publishing House of Wrocław University of Economics, pp. 43-57.

BOĎA, M. and KANDEROVÁ, M. 2018. What is the true effect of realancing - a higher return or a lower risk? Acta Universitatis Agriculturae et Silviculturae Mendelianae Brunensis, 66(6): 1417-1430.

BOĎA, M. and ROHÁČOVÁ, V. 2014. Application of Six Sigma ideas to timing decisions at financial markets. In: 17-th AMSE. Applications of Mathematics in Economics. Conference proceedings full text papers. 27-31 August: Jerzmanowice. Wrocław: Publishing House of Wrocław University of Economics, pp. 36-45.

BOUCHEY, P. et al. 2012. Volatility harvesting: Why does diversifying and rebalancing create portfolio growth? The Journal of Wealth Management, 15(2): 26-35.

DE JONG, F. and DRIESSEN, J. 2013. The Norwegian government pension fund's potential for capturing illiquidity premiums. Research report for the Norwegian Ministry of Finance. Available at: http:// dx.doi.org/10.2139/ssrn.2337939 [Accessed: 2020, November 15].

DICHTL, H., DROBETZ, W. and WAMBACH, M. 2014. Where is the value added of rebalancing? A systematic comparison of alternative rebalancing strategies. Financial Markets and Portfolio Management, 28(3): 209-231.

DICHTL, H., DROBETS, W. and WAMBACH, M. 2016. Testing rebalancing strategies for stock-bond portfolios across different asset allocations. Applied Economics, 48(9): 772-788.

DOUKAS, J. A., KIM, C. F. and PANTZALIS, C. 2002. A test of the errors-in-expectations explanation of the value/glamour stock returns performance: evidence from analysts' forecasts. The Journal of Finance, 57(5): 2143-2165.

DOYLE, B., MEFFORD, R. and TAY, N. S. P. 2010. What financial risk managers can learn from Six Sigma quality programs. Working paper. Available at: http://repository.usfca.edu/fe/2 [Accessed: 2020, November 15].

FABOZZI, F. J. 1998. Overview of equity style management. In: FABOZZI, F. J. (Ed.). Active equity portfolio management. New Hope, PA: Frank J. Fabozzi Associates, pp. 57-70.

GLEN, J. J. 2011. Mean-variance portfolio rebalancing with transaction costs and funding changes. Journal of the Operational Research Society, 62(4): 667-676.

GROBYS, K. 2010. Correlation versus cointegration: do cointegrated based index-tracking portfolios perform better? Zeitschrift für Nachwuchswissenschaftler, 1(2): 72-78.

GUSTAROBA, G., MANSINI, R. and SPERANZA, M. G. 2009. Models and simulations for portfolio rebalancing. Computational Economics, 33: 237-262. 
HARJOTO, M. A. and JONES, F. J. 2006. Rebalancing strategy for stocks and bonds asset allocation. The Journal of Wealth Management, 9(1): 37-44.

IONESCU, G. 2002. Portfolio construction strategies using cointegration. Dissertation thesis. Bucharest: Academy of Economic Studies Doctoral School of Finance and Banking, 2002.

KWAK, Y. H., and ANBARI, F. T. 2006. Benefits, obstacles, and future of six sigma approach. Technovation, 26(5-6): 708-715.

LAM, M. 2014. Is portfolio rebalancing good for investors? Thesis submitted in partial fulfilment of the requirements for the degree of Master of Science in Business Administration. Prince George, Canada: University of Northern British Columbia.

LEVIS, M. The record on small companies: A review of the evidence. Journal of Asset Management, 2(4): 368-397.

MANSINI, R., OGRYCZAK, W. and SPERANZA, M. G. 2015. Linear and mixed integer programming for portfolio optimization. Cham, Switzerland: Springer.

MEFFORD, R. N., TAY, N. S. P., DOYLE, B. and OHARA, F. 2017. Portfolio risk management using Six Sigma quality principles. Quality Management Journal, 24(2): 6-30.

MONTGOMERY, D.C. 2001. Introduction to statistical quality control. $4^{\text {th }}$ Edition. New York: Wiley.

PETERSON, B. G. et al. 2014. PerformanceAnalytics: econometric tools for performance and risk analysis. $\mathrm{R}$ package, version 1.4.3541. Available at: http://cran.r-project.org/web/packages/Performance Analytics/ index.html [Accessed: 2020, November 15].

PLAXCO, L. M. and ARNOTT, R. D. 2002. Rebalancing a global policy benchmark. The Journal of Portfolio Management, 28(2): 9-22.

RYAN, A. J., ULRICH, J. M., THIELEN, W. and TEETOR, P. 2017. quantmod: Quantitative financial modelling framework R package, version 0.4-12. Available at: http://cran.r-project.org/web/packages/ quantmod/index.html [Accessed: 2020, November 15].

R CORE TEAM. 2014. R: a language and environment for statistical computing. Vienna: R Foundation for Statistical Computing.

SCHROEDER, R. G. et al. 2008. Six Sigma: definition and underlying theory. Journal of Operations Management, 26(4): 536-554.

SWITZER, L. N. 2010. The behaviour of small cap vs. large cap stocks in recessions and recoveries: Empirical evidence for the United States and Canada. The North American Journal of Economics and Finance, 21(3): 332-346.

TSAI, C. 2001. Rebalancing diversified portfolios of various risk profiles. The Journal of Financial Planning, 14(10): 104-110.

ZU, X., FREDENDALL, L. D. and DOUGLAS, T. J. 2008. The evolving theory of quality management: The role of Six Sigma. Journal of Operations Management, 26(5): 630-650.

WILLENBROCK, S. 2011. Diversification, return, portfolio rebalancing, and the commodity return puzzle. The Financial Analysts Journal, 67(4): 42-49.

WUERTZ, D. and CHALABI, Y. 2013. timeSeries: Rmetrics - financial time series objects. R package, version 3010.97. Available at: http://cran.r-project.org/web/packages/timeSeries/index.html [Accessed: 2020, November 15].

Martin Bod'a: martin.boda@outlook.com Mária Kanderová: maria.kanderova@umb.sk 
APPENDIX

Appendix A: Performance of rebalancing strategies averaged for different portfolio nominal sizes

\begin{tabular}{|c|c|c|c|c|c|c|c|c|c|}
\hline \multirow[t]{2}{*}{ Style } & \multirow[t]{2}{*}{ Period } & \multirow[t]{2}{*}{ Strategy } & $\begin{array}{l}\text { Mean } \\
\text { return }\end{array}$ & Volatility & Performance & $\begin{array}{c}\text { Mean active } \\
\text { return }\end{array}$ & $\begin{array}{c}\text { Active } \\
\text { volatility }\end{array}$ & $\begin{array}{c}\text { Active } \\
\text { performance }\end{array}$ & \multirow{2}{*}{$\begin{array}{l}\text { Net compound } \\
\text { return }\end{array}$} \\
\hline & & & [Ret] & [Vol] & Ret/Vol & [ARet] & [AVol] & ARet/AVol & \\
\hline B & 20112014 & $\mathrm{BH}$ & $15.12 \%$ & $9.07 \%$ & 1.6674 & $-1.47 \%$ & $14.46 \%$ & -0.1038 & $15.42 \%$ \\
\hline B & 20112014 & D0.000 & $15.50 \%$ & $9.32 \%$ & 1.6614 & $-1.09 \%$ & $14.56 \%$ & -0.0755 & $14.31 \%$ \\
\hline B & 20112014 & D0.015 & $16.42 \%$ & $9.26 \%$ & 1.7725 & $-0.17 \%$ & $14.65 \%$ & -0.0128 & $16.38 \%$ \\
\hline B & 20112014 & D0.030 & $16.38 \%$ & $8.91 \%$ & 1.8397 & $-0.21 \%$ & $14.17 \%$ & -0.0165 & $16.58 \%$ \\
\hline B & 20112014 & D0.045 & $15.22 \%$ & $9.08 \%$ & 1.6768 & $-1.37 \%$ & $14.49 \%$ & -0.0960 & $15.45 \%$ \\
\hline B & 20112014 & D0.060 & $15.20 \%$ & $9.00 \%$ & 1.6877 & $-1.39 \%$ & $14.39 \%$ & -0.0991 & $15.46 \%$ \\
\hline B & 20112014 & SS & $15.09 \%$ & $9.06 \%$ & 1.6687 & $-1.50 \%$ & $14.56 \%$ & -0.1035 & $15.19 \%$ \\
\hline B & 20122015 & $\mathrm{BH}$ & $4.79 \%$ & $12.33 \%$ & 0.3967 & $-2.35 \%$ & $18.60 \%$ & -0.1245 & $4.52 \%$ \\
\hline B & 20122015 & D0.000 & $4.10 \%$ & $11.91 \%$ & 0.3415 & $-3.04 \%$ & $18.66 \%$ & -0.1646 & $2.34 \%$ \\
\hline B & 20122015 & D0.015 & $5.00 \%$ & $12.06 \%$ & 0.4114 & $-2.14 \%$ & $18.89 \%$ & -0.1173 & $4.04 \%$ \\
\hline B & 20122015 & D0.030 & $4.52 \%$ & $11.99 \%$ & 0.3820 & $-2.62 \%$ & $18.93 \%$ & -0.1386 & $3.92 \%$ \\
\hline B & 20122015 & D0.045 & $3.35 \%$ & $12.04 \%$ & 0.2890 & $-3.79 \%$ & $18.70 \%$ & -0.1982 & $2.98 \%$ \\
\hline B & 20122015 & D0.060 & $4.79 \%$ & $12.33 \%$ & 0.3967 & $-2.35 \%$ & $18.60 \%$ & -0.1245 & $4.52 \%$ \\
\hline B & 20122015 & SS & $3.89 \%$ & $11.79 \%$ & 0.3355 & $-3.25 \%$ & $18.55 \%$ & -0.1739 & $2.79 \%$ \\
\hline B & 20132016 & $\mathrm{BH}$ & $3.69 \%$ & $13.02 \%$ & 0.2853 & $-2.33 \%$ & $19.58 \%$ & -0.1186 & $3.41 \%$ \\
\hline B & 20132016 & D0.000 & $2.43 \%$ & $12.46 \%$ & 0.1937 & $-3.58 \%$ & $18.91 \%$ & -0.1912 & $0.64 \%$ \\
\hline B & 20132016 & D0.015 & $2.82 \%$ & $12.31 \%$ & 0.2256 & $-3.20 \%$ & $18.82 \%$ & -0.1721 & $1.92 \%$ \\
\hline B & 20132016 & D0.030 & $4.06 \%$ & $12.82 \%$ & 0.3189 & $-1.96 \%$ & $19.28 \%$ & -0.1000 & $3.44 \%$ \\
\hline B & 20132016 & D0.045 & $3.85 \%$ & $12.90 \%$ & 0.2987 & $-2.17 \%$ & $19.55 \%$ & -0.1115 & $3.46 \%$ \\
\hline B & 20132016 & D0.060 & $3.69 \%$ & $13.02 \%$ & 0.2853 & $-2.33 \%$ & $19.58 \%$ & -0.1186 & $3.41 \%$ \\
\hline B & 20132016 & SS & $3.74 \%$ & $12.21 \%$ & 0.3066 & $-2.28 \%$ & $18.58 \%$ & -0.1229 & $2.31 \%$ \\
\hline B & 20142017 & $\mathrm{BH}$ & $11.80 \%$ & $7.63 \%$ & 1.5431 & $-4.93 \%$ & $10.56 \%$ & -0.4733 & $11.81 \%$ \\
\hline B & 20142017 & D0.000 & $11.80 \%$ & $7.99 \%$ & 1.4763 & $-4.93 \%$ & $11.25 \%$ & -0.4412 & $10.43 \%$ \\
\hline B & 20142017 & D0.015 & $11.86 \%$ & $8.06 \%$ & 1.4817 & $-4.87 \%$ & $10.84 \%$ & -0.4528 & $11.28 \%$ \\
\hline B & 20142017 & D0.030 & $12.35 \%$ & $7.91 \%$ & 1.5624 & $-4.38 \%$ & $11.03 \%$ & -0.3990 & $12.07 \%$ \\
\hline B & 20142017 & D0.045 & $12.22 \%$ & $7.85 \%$ & 1.5485 & $-4.51 \%$ & $10.80 \%$ & -0.4336 & $12.24 \%$ \\
\hline B & 20142017 & D0.060 & $11.80 \%$ & $7.63 \%$ & 1.5431 & $-4.93 \%$ & $10.56 \%$ & -0.4733 & $11.81 \%$ \\
\hline B & 20142017 & SS & $12.62 \%$ & $7.85 \%$ & 1.6104 & $-4.11 \%$ & $10.72 \%$ & -0.3857 & $12.12 \%$ \\
\hline S & 20112014 & $\mathrm{BH}$ & $24.57 \%$ & $15.27 \%$ & 1.7402 & $7.98 \%$ & $20.40 \%$ & 0.4238 & $26.50 \%$ \\
\hline$S$ & 20112014 & D0.000 & $21.79 \%$ & $13.59 \%$ & 1.5995 & $5.20 \%$ & $18.80 \%$ & 0.2749 & $21.99 \%$ \\
\hline$S$ & 20112014 & D0.015 & $22.18 \%$ & $13.04 \%$ & 1.6656 & $5.59 \%$ & $18.16 \%$ & 0.2814 & $22.92 \%$ \\
\hline$S$ & 20112014 & D0.030 & $21.18 \%$ & $13.16 \%$ & 1.5956 & $4.59 \%$ & $17.88 \%$ & 0.2304 & $22.28 \%$ \\
\hline S & 20112014 & D0.045 & $22.15 \%$ & $13.18 \%$ & 1.7264 & $5.56 \%$ & $17.60 \%$ & 0.3124 & $23.56 \%$ \\
\hline S & 20112014 & D0.060 & $22.30 \%$ & $13.80 \%$ & 1.6285 & $5.71 \%$ & $18.56 \%$ & 0.2872 & $23.91 \%$ \\
\hline$S$ & 20112014 & SS & $24.11 \%$ & $15.53 \%$ & 1.6696 & $7.52 \%$ & $20.63 \%$ & 0.3939 & $25.82 \%$ \\
\hline$S$ & 20122015 & $\mathrm{BH}$ & $7.42 \%$ & $13.13 \%$ & 0.5695 & $0.28 \%$ & $19.43 \%$ & 0.0055 & $7.20 \%$ \\
\hline$S$ & 20122015 & D0.000 & $3.93 \%$ & $12.77 \%$ & 0.3449 & $-3.21 \%$ & $19.47 \%$ & -0.1525 & $2.28 \%$ \\
\hline$S$ & 20122015 & D0.015 & $4.09 \%$ & $13.56 \%$ & 0.3402 & $-3.05 \%$ & $20.12 \%$ & -0.1393 & $2.96 \%$ \\
\hline S & 20122015 & D0.030 & $3.60 \%$ & $13.57 \%$ & 0.3002 & $-3.54 \%$ & $20.26 \%$ & -0.1606 & $2.81 \%$ \\
\hline S & 20122015 & D0.045 & $4.92 \%$ & $13.04 \%$ & 0.4143 & $-2.22 \%$ & $19.46 \%$ & -0.1012 & $4.47 \%$ \\
\hline S & 20122015 & D0.060 & $4.73 \%$ & $12.86 \%$ & 0.4127 & $-2.41 \%$ & $19.28 \%$ & -0.1098 & $4.32 \%$ \\
\hline S & 20122015 & SS & $5.37 \%$ & $12.50 \%$ & 0.4526 & $-1.77 \%$ & $19.11 \%$ & -0.0844 & $4.14 \%$ \\
\hline
\end{tabular}




\begin{tabular}{|c|c|c|c|c|c|c|c|c|c|}
\hline \multirow[t]{2}{*}{ Style } & \multirow[t]{2}{*}{ Period } & \multirow[t]{2}{*}{ Strategy } & $\begin{array}{l}\text { Mean } \\
\text { return }\end{array}$ & Volatility & Performance & $\begin{array}{c}\text { Mean active } \\
\text { return }\end{array}$ & $\begin{array}{c}\text { Active } \\
\text { volatility }\end{array}$ & $\begin{array}{c}\text { Active } \\
\text { performance }\end{array}$ & \multirow{2}{*}{$\begin{array}{l}\text { Net compound } \\
\text { return }\end{array}$} \\
\hline & & & [Ret] & [Vol] & Ret/Vol & [ARet] & [AVol] & ARet/AVol & \\
\hline S & 20132016 & $\mathrm{BH}$ & $1.13 \%$ & $15.52 \%$ & 0.1352 & $-4.89 \%$ & $20.52 \%$ & -0.2153 & $0.99 \%$ \\
\hline S & 20132016 & D0.000 & $-4.68 \%$ & $16.70 \%$ & -0.2584 & $-10.70 \%$ & $21.40 \%$ & -0.4907 & $-5.95 \%$ \\
\hline S & 20132016 & D0.015 & $-4.94 \%$ & $17.83 \%$ & -0.2663 & $-10.96 \%$ & $22.61 \%$ & -0.4836 & $-5.75 \%$ \\
\hline S & 20132016 & D0.030 & $-0.02 \%$ & $16.25 \%$ & 0.0697 & $-6.04 \%$ & $21.15 \%$ & -0.2577 & $-0.39 \%$ \\
\hline S & 20132016 & D0.045 & $-0.45 \%$ & $15.53 \%$ & 0.0362 & $-6.47 \%$ & $20.27 \%$ & -0.2936 & $-0.56 \%$ \\
\hline S & 20132016 & D0.060 & $1.36 \%$ & $15.63 \%$ & 0.1666 & $-4.66 \%$ & $20.53 \%$ & -0.1985 & $1.18 \%$ \\
\hline S & 20132016 & SS & $0.83 \%$ & $15.08 \%$ & 0.1331 & $-5.19 \%$ & $20.23 \%$ & -0.2281 & $-0.33 \%$ \\
\hline S & 20142017 & $\mathrm{BH}$ & $7.90 \%$ & $15.84 \%$ & 0.4906 & $-8.83 \%$ & $17.93 \%$ & -0.4939 & $7.94 \%$ \\
\hline S & 20142017 & D0.000 & $7.74 \%$ & $15.40 \%$ & 0.5295 & $-8.98 \%$ & $17.30 \%$ & -0.5308 & $6.77 \%$ \\
\hline S & 20142017 & D0.015 & $5.95 \%$ & $14.93 \%$ & 0.3753 & $-10.77 \%$ & $16.79 \%$ & -0.6686 & $5.10 \%$ \\
\hline S & 20142017 & D0.030 & $4.98 \%$ & $15.62 \%$ & 0.3186 & $-11.75 \%$ & $17.82 \%$ & -0.6692 & $4.38 \%$ \\
\hline S & 20142017 & D0.045 & $7.18 \%$ & $16.34 \%$ & 0.4500 & $-9.55 \%$ & $18.32 \%$ & -0.5249 & $6.85 \%$ \\
\hline S & 20142017 & D0.060 & $6.62 \%$ & $16.59 \%$ & 0.4134 & $-10.10 \%$ & $18.75 \%$ & -0.5389 & $6.27 \%$ \\
\hline$S$ & 20142017 & SS & $7.54 \%$ & $15.45 \%$ & 0.5168 & $-9.19 \%$ & $17.51 \%$ & -0.5228 & $7.14 \%$ \\
\hline G & 20112014 & $\mathrm{BH}$ & $15.99 \%$ & $8.79 \%$ & 1.8244 & $-0.60 \%$ & $14.04 \%$ & -0.0485 & $16.41 \%$ \\
\hline G & 20112014 & D0.000 & $17.15 \%$ & $9.68 \%$ & 1.7805 & $0.56 \%$ & $15.03 \%$ & 0.0364 & $16.26 \%$ \\
\hline G & 20112014 & D0.015 & $17.09 \%$ & $9.12 \%$ & 1.8859 & $0.50 \%$ & $14.54 \%$ & 0.0326 & $17.11 \%$ \\
\hline G & 20112014 & D0.030 & $17.01 \%$ & $8.91 \%$ & 1.9249 & $0.42 \%$ & $14.46 \%$ & 0.0305 & $17.23 \%$ \\
\hline G & 20112014 & D0.045 & $15.99 \%$ & $8.96 \%$ & 1.7931 & $-0.60 \%$ & $14.37 \%$ & -0.0440 & $16.31 \%$ \\
\hline G & 20112014 & D0.060 & $15.92 \%$ & $8.91 \%$ & 1.7945 & $-0.67 \%$ & $14.18 \%$ & -0.0516 & $16.27 \%$ \\
\hline G & 20112014 & SS & $17.28 \%$ & $9.14 \%$ & 1.8891 & $0.69 \%$ & $14.67 \%$ & 0.0448 & $17.34 \%$ \\
\hline G & 20122015 & $\mathrm{BH}$ & $6.49 \%$ & $12.53 \%$ & 0.5307 & $-0.65 \%$ & $18.75 \%$ & -0.0312 & $6.27 \%$ \\
\hline G & 20122015 & D0.000 & $7.52 \%$ & $12.37 \%$ & 0.6126 & $0.38 \%$ & $18.87 \%$ & 0.0208 & $6.20 \%$ \\
\hline G & 20122015 & D0.015 & $7.05 \%$ & $11.78 \%$ & 0.6027 & $-0.09 \%$ & $18.19 \%$ & -0.0036 & $6.43 \%$ \\
\hline G & 20122015 & D0.030 & $6.73 \%$ & $11.64 \%$ & 0.5918 & $-0.41 \%$ & $18.20 \%$ & -0.0186 & $6.29 \%$ \\
\hline G & 20122015 & D0.045 & $6.23 \%$ & $12.43 \%$ & 0.5134 & $-0.91 \%$ & $18.70 \%$ & -0.0450 & $5.96 \%$ \\
\hline G & 20122015 & D0.060 & $6.38 \%$ & $12.46 \%$ & 0.5240 & $-0.76 \%$ & $18.65 \%$ & -0.0376 & $6.11 \%$ \\
\hline G & 20122015 & SS & $6.41 \%$ & $11.80 \%$ & 0.5505 & $-0.72 \%$ & $18.32 \%$ & -0.0378 & $5.47 \%$ \\
\hline G & 20132016 & $\mathrm{BH}$ & $3.23 \%$ & $11.65 \%$ & 0.2830 & $-2.78 \%$ & $18.02 \%$ & -0.1561 & $2.96 \%$ \\
\hline G & 20132016 & D0.000 & $4.08 \%$ & $11.99 \%$ & 0.3412 & $-1.93 \%$ & $18.03 \%$ & -0.1064 & $2.45 \%$ \\
\hline G & 20132016 & D0.015 & $4.59 \%$ & $11.61 \%$ & 0.3959 & $-1.43 \%$ & $17.82 \%$ & -0.0798 & $3.81 \%$ \\
\hline G & 20132016 & D0.030 & $3.87 \%$ & $11.52 \%$ & 0.3379 & $-2.15 \%$ & $17.70 \%$ & -0.1216 & $3.34 \%$ \\
\hline G & 20132016 & D0.045 & $4.79 \%$ & $11.61 \%$ & 0.4138 & $-1.23 \%$ & $18.08 \%$ & -0.0685 & $4.29 \%$ \\
\hline G & 20132016 & D0.060 & $3.65 \%$ & $11.68 \%$ & 0.3171 & $-2.37 \%$ & $17.94 \%$ & -0.1340 & $3.34 \%$ \\
\hline G & 20132016 & SS & $4.12 \%$ & $12.09 \%$ & 0.3421 & $-1.90 \%$ & $17.99 \%$ & -0.1047 & $2.92 \%$ \\
\hline G & 20142017 & $\mathrm{BH}$ & $14.27 \%$ & $8.06 \%$ & 1.7632 & $-2.46 \%$ & $10.63 \%$ & -0.2329 & $14.51 \%$ \\
\hline G & 20142017 & D0.000 & $15.37 \%$ & $7.91 \%$ & 1.9393 & $-1.36 \%$ & $10.51 \%$ & -0.1307 & $14.45 \%$ \\
\hline G & 20142017 & D0.015 & $15.66 \%$ & $7.49 \%$ & 2.0807 & $-1.07 \%$ & $10.47 \%$ & -0.1074 & $15.59 \%$ \\
\hline G & 20142017 & D0.030 & $15.52 \%$ & $7.86 \%$ & 1.9753 & $-1.21 \%$ & $10.45 \%$ & -0.1181 & $15.65 \%$ \\
\hline G & 20142017 & D0.045 & $14.27 \%$ & $8.06 \%$ & 1.7632 & $-2.46 \%$ & $10.63 \%$ & -0.2329 & $14.51 \%$ \\
\hline G & 20142017 & D0.060 & $14.27 \%$ & $8.06 \%$ & 1.7632 & $-2.46 \%$ & $10.63 \%$ & -0.2329 & $14.51 \%$ \\
\hline $\mathrm{G}$ & 20142017 & SS & $15.84 \%$ & $7.44 \%$ & 2.1268 & $-0.89 \%$ & $10.11 \%$ & -0.0913 & $15.63 \%$ \\
\hline
\end{tabular}




\begin{tabular}{|c|c|c|c|c|c|c|c|c|c|}
\hline \multirow[t]{2}{*}{ Style } & \multirow[t]{2}{*}{ Period } & \multirow[t]{2}{*}{ Strategy } & $\begin{array}{l}\text { Mean } \\
\text { return }\end{array}$ & Volatility & Performance & $\begin{array}{c}\text { Mean active } \\
\text { return }\end{array}$ & $\begin{array}{c}\text { Active } \\
\text { volatility }\end{array}$ & $\begin{array}{c}\text { Active } \\
\text { performance } \\
\end{array}$ & \multirow{2}{*}{$\begin{array}{l}\text { Net compound } \\
\text { return }\end{array}$} \\
\hline & & & [Ret] & [Vol] & Ret/Vol & [ARet] & [AVol] & ARet/AVol & \\
\hline $\mathrm{V}$ & 20112014 & $\mathrm{BH}$ & $15.66 \%$ & $8.83 \%$ & 1.7758 & $-0.93 \%$ & $14.55 \%$ & -0.0633 & $16.04 \%$ \\
\hline V & 20112014 & D0.000 & $15.78 \%$ & $9.03 \%$ & 1.7580 & $-0.81 \%$ & $14.89 \%$ & -0.0528 & $14.84 \%$ \\
\hline V & 20112014 & D0.015 & $16.35 \%$ & $9.14 \%$ & 1.7896 & $-0.24 \%$ & $15.01 \%$ & -0.0155 & $16.33 \%$ \\
\hline V & 20112014 & D0.030 & $15.98 \%$ & $9.07 \%$ & 1.7751 & $-0.61 \%$ & $14.91 \%$ & -0.0363 & $16.20 \%$ \\
\hline V & 20112014 & D0.045 & $15.66 \%$ & $8.88 \%$ & 1.7690 & $-0.93 \%$ & $14.64 \%$ & -0.0618 & $16.00 \%$ \\
\hline V & 20112014 & D0.060 & $15.66 \%$ & $8.83 \%$ & 1.7758 & $-0.93 \%$ & $14.55 \%$ & -0.0633 & $16.04 \%$ \\
\hline $\mathrm{V}$ & 20112014 & SS & $16.38 \%$ & $8.90 \%$ & 1.8456 & $-0.20 \%$ & $14.76 \%$ & -0.0161 & $16.53 \%$ \\
\hline V & 20122015 & $\mathrm{BH}$ & $4.01 \%$ & $11.77 \%$ & 0.3421 & $-3.13 \%$ & $18.45 \%$ & -0.1691 & $3.74 \%$ \\
\hline $\mathrm{V}$ & 20122015 & D0.000 & $4.18 \%$ & $12.45 \%$ & 0.3356 & $-2.96 \%$ & $19.01 \%$ & -0.1552 & $2.47 \%$ \\
\hline V & 20122015 & D0.015 & $3.76 \%$ & $12.40 \%$ & 0.3032 & $-3.38 \%$ & $19.24 \%$ & -0.1755 & $2.96 \%$ \\
\hline $\mathrm{V}$ & 20122015 & D0.030 & $4.25 \%$ & $11.88 \%$ & 0.3571 & $-2.89 \%$ & $18.61 \%$ & -0.1560 & $3.86 \%$ \\
\hline V & 20122015 & D0.045 & $4.46 \%$ & $11.86 \%$ & 0.3767 & $-2.68 \%$ & $18.60 \%$ & -0.1442 & $4.16 \%$ \\
\hline V & 20122015 & D0.060 & $4.11 \%$ & $11.75 \%$ & 0.3509 & $-3.02 \%$ & $18.48 \%$ & -0.1632 & $3.82 \%$ \\
\hline $\mathrm{V}$ & 20122015 & SS & $5.26 \%$ & $12.10 \%$ & 0.4357 & $-1.88 \%$ & $18.66 \%$ & -0.1002 & $4.21 \%$ \\
\hline $\mathrm{V}$ & 20132016 & $\mathrm{BH}$ & $2.64 \%$ & $13.28 \%$ & 0.2014 & $-3.38 \%$ & $19.68 \%$ & -0.1715 & $2.37 \%$ \\
\hline $\mathrm{V}$ & 20132016 & D0.000 & $4.25 \%$ & $12.71 \%$ & 0.3319 & $-1.76 \%$ & $19.02 \%$ & -0.0934 & $2.79 \%$ \\
\hline $\mathrm{V}$ & 20132016 & D0.015 & $3.79 \%$ & $12.50 \%$ & 0.2984 & $-2.23 \%$ & $18.88 \%$ & -0.1208 & $3.13 \%$ \\
\hline V & 20132016 & D0.030 & $2.87 \%$ & $12.74 \%$ & 0.2266 & $-3.15 \%$ & $19.00 \%$ & -0.1664 & $2.38 \%$ \\
\hline V & 20132016 & D0.045 & $2.07 \%$ & $13.12 \%$ & 0.1593 & $-3.94 \%$ & $19.47 \%$ & -0.2027 & $1.75 \%$ \\
\hline $\mathrm{V}$ & 20132016 & D0.060 & $2.30 \%$ & $13.31 \%$ & 0.1753 & $-3.72 \%$ & $19.61 \%$ & -0.1891 & $2.00 \%$ \\
\hline $\mathrm{V}$ & 20132016 & SS & $4.33 \%$ & $12.49 \%$ & 0.3446 & $-1.69 \%$ & $18.89 \%$ & -0.0900 & $3.33 \%$ \\
\hline $\mathrm{V}$ & 20142017 & BH & $6.09 \%$ & $8.87 \%$ & 0.7658 & $-10.64 \%$ & $10.47 \%$ & -1.0075 & $5.87 \%$ \\
\hline $\mathrm{V}$ & 20142017 & D0.000 & $12.70 \%$ & $9.37 \%$ & 1.4281 & $-4.03 \%$ & $10.96 \%$ & -0.3397 & $11.25 \%$ \\
\hline V & 20142017 & D0.015 & $10.21 \%$ & $8.37 \%$ & 1.2620 & $-6.52 \%$ & $10.15 \%$ & -0.6266 & $9.50 \%$ \\
\hline V & 20142017 & D0.030 & $10.06 \%$ & $8.93 \%$ & 1.1672 & $-6.67 \%$ & $10.61 \%$ & -0.6139 & $9.64 \%$ \\
\hline V & 20142017 & D0.045 & $7.62 \%$ & $8.53 \%$ & 0.9347 & $-9.11 \%$ & $10.05 \%$ & -0.9082 & $7.12 \%$ \\
\hline $\mathrm{V}$ & 20142017 & D0.060 & $6.56 \%$ & $8.53 \%$ & 0.8053 & $-10.17 \%$ & $10.34 \%$ & -0.9845 & $6.24 \%$ \\
\hline $\mathrm{V}$ & 20142017 & SS & $10.87 \%$ & $9.54 \%$ & 1.1792 & $-5.86 \%$ & $11.14 \%$ & -0.5213 & $10.47 \%$ \\
\hline
\end{tabular}

Legend: "B", "S" indicate investment styles arising from investing solely into big caps and small caps, respectively. "BH" stands for the buy-and-hold strategy, "D" denotes a deviation rebalancing strategy with the choice of treshold that is appended on the right side, "SS" is the Six Sigma rebalancing strategy.

Note: "D0.000" coincides with periodic rebalancing.

Legend: "G", "V" indicate investment styles arising from investing solely into growth stocks and value stocks, respectively. "BH" stands for the buy-and-hold strategy, "D" denotes a deviation rebalancing strategy with the choice of treshold that is appended on the right side, "SS" is the Six Sigma rebalancing strategy.

Note: "D0.000" coincides with periodic rebalancing. 